\title{
The Identification of Motivational Factors That Influences Nurses Output in Hospitals in the Fako Division, Cameroon
}

\author{
Samuel Nambile Cumber ${ }^{1,2, *}$, Stanly Mbua Elive $\mathrm{e}^{2,3}$ \\ ${ }^{1}$ Discipline of Public Health Medicine, Department of Nursing \& Public Health, College of Health Sciences, University of Kwazulu-Natal, \\ Durban, South Africa \\ ${ }^{2}$ Under Privileged Children and Women Assistance (UPCAWA-SWEDEN), Buea, Cameroon \\ ${ }^{3}$ Department of Nursing, Faculty of Health Science, University of Buea, Buea, Cameroon
}

Email address:

samuelcumber@yahoo.com (S. N. Cumber)

${ }^{*}$ Corresponding author

\section{To cite this article:}

Samuel Nambile Cumber, Stanly Mbua Elive. The Identification of Motivational Factors That Influences Nurses Output in Hospitals in the Fako Division, Cameroon. Journal of Family Medicine and Health Care. Vol. 2, No. 4, 2016, pp. 74-80. doi: 10.11648/j.jfmhc.20160204.18

Received: September 17, 2016; Accepted: October 15, 2016; Published: November 23, 2016

\begin{abstract}
The importance of motivation in the day-to-day performance of nurses' cannot be over emphasized; it is a wellknown fact that human output of any sort is improved by increase in motivation. To identify motivational factors that influences nurses output in health institutions in Fako Division. We used a descriptive survey in health institutions in Fako Division from Oct 2014 - May, 2015. Data was collected using a self administered questionnaire. Data was analyzed using Epi Info version 3.1, and SPSS version 21.0. The level of statistical significance was set at a $\mathrm{P}$ value $<0.05$ at a $95 \%$ Confidence Level. We included 185 participants of which 151(81.6\%) were female participants. The most involved were nurse assistant (32.4\%) and most nurses had 5 years experience and more 72(38.9\%). It was seen that recognition of work done is ranked the first of the motivated intrinsic factors with (91.4\%) while for extrinsic motivation, majority of the nurses agreed that increase in salary and bonus is the most motivating factor with (84.9\%). Finally, it was shown that nurses' valued intrinsic motivation $(82.8 \%)$ more than extrinsic motivation $(59.4 \%)$. Nurses choose the profession out of passion. The two factors of motivation have an influence on nurses' output; intrinsic motivation is seen as the dominant and most requested motivated factor by nurses with more emphasis on recognition and promotion. Followed by extrinsic motivation with the most emphasis placed on salaries and bonuses, there is a statistical difference as nurses in the private hospitals desired extrinsic motivation more. We recommended that nurses should enter this profession for passion and the health administration should promote intrinsic motivation more as compared to extrinsic motivation.
\end{abstract}

Keywords: Identification, Motivation, Nurses', Output, Factors, Cameroon

\section{Background}

The principal concern of any organization is to ensure maximum output among its employees and yield greater productivity in the organization. Globally, for any organizations to meet the standards of performance the employees are expected to work effectively, this can be attained if they are well motivated. In addition, employees output is very important, not only for the growth of the organization, but also for the growth of individual employee [1]. There are several reasons why people decide to do nursing, The desire to help or care for others and to contribute to society is reported as dominant factors influencing this choice $[2,3]$. On this basis it is important to know what really motivates nurses to render adequate services

With the main objective to identify motivational factors that influence nurses' output,

This paper focuses on Herzberg theory [4]. Herzberg [4] made it clear that there are two factors of motivation which can influence an employee's output. These are intrinsic and extrinsic factors. White studied intrinsic motivation and found that it helped in the enhancement of personal efforts as well as having an influence on employee behavior [5]. With such diverse motivational factors, health administrators face challenges in designing the motivational tools appropriate for 
nurses to meet the predictable performance of their institutions. According to Herzberg [4]

Table 1. Motivational factors.

\begin{tabular}{ll}
\hline Intrinsic Motivation & Extrinsic Motivation \\
Achievement & Working condition \\
-Recognition & -Salary \\
-Responsibility & -Organization /Administration policies \\
-The nature of work itself & -Supervision \\
-Promotion & -Interpersonal relationships \\
\hline
\end{tabular}

Intrinsic motivation is considered as "motivation within". It is defined as the doing of an activity for personal satisfactions; improve performance, feeling of selffulfillment, achievement and recognition. When a person is motivated intrinsically, he moves to act for the fun or challenge which is involved [5].

Autonomy and responsibility enhance nurse retention. The organization that has autonomous and long-serving nurses, provide quality care to patients cost-effectively and this could further help to reduce turnover rates among nurses. This further explains that, nurses feel motivated when they know responsibility is bestowed on them [6].

Decision making is another important aspect which concerns intrinsic motivation Tang [7] said nurses should be encouraged to participate in decision-making regarding the formulation of policies and the implementation of changes in a specific unit. If nurses are involved in decision-making processes, they might experience higher levels of job satisfaction and might stay longer in a specific organization

Extrinsic motivation thus contrasts with intrinsic motivation, which refers to doing an activity simply for the enjoyment of the activity itself, unlike some perspectives that view extrinsically motivated behavior as invariantly non autonomous, it is external in nature, and can vary greatly in the degree to which it is autonomous [8]. The most wellknown and the most debated motivation is money.

Some aspects of nurses job satisfaction which are indirect working environment and direct working environment includes salary and promotion, self-growth, challenging work, interaction and feedback with patients and family members, leadership style, working atmosphere, and family support and religion. But of all these, salary and wok condition were considered as the main aspects that increase job satisfaction among nurses [9].

\section{Methodology}

\subsection{Study Design}

A cross sectional descriptive survey was used.

\subsection{Study Duration}

This study was carried out over a period of 8 months (October 2014 - May 2015).

\subsection{Study Setting}

This study was carried out in Fako Division in the south west region of the republic of Cameroon. The hospitals in Fako Division are divided into three categories (Public, Private and Mission). We have a total of 13 hospitals (5 Public, 3 Private and 5 Mission). We decided to sample these hospitals to arrive at our desired sample size. The selected hospitals were;

The Public hospitals were Buea Regional Hospital (BRH), Limbe Regional Hospital (LRH), Muyuka District Hospital $(\mathrm{MDH})$;

The private hospitals included Solidarity Clinic (SC) and St. Luke's Medical Center (SLMC), and Mission hospitals were Baptist Hospital Mutengene (BHM), Mount Mary Hospital (MMH), and Regina Pacis mutengene (RPM).

\subsection{Study Population}

Our study population constituted all nurses working in these hospitals in the Fako Division.

\subsubsection{Inclusion Criteria}

- All respondents were workers in a recognized institution and in active service.

- All nurses were of ages 21 years and above.

\subsubsection{Exclusion Criteria}

- All nurses who were not willing to give their consent freely.

\subsection{Sampling Method}

- Sample Selection

Simple random sampling method was used to select the institutions through the hat and draw procedure in order to reduce bias and gave each institution an equal chance of been selected.

- Sample size calculation

The sample size will be gotten from the formula, Fishers (1998) as follows.:

$$
\mathrm{n}_{\mathrm{o}}=\frac{Z^{2} \boldsymbol{p} \boldsymbol{q}}{d^{2}}
$$

Where

$\mathrm{n}_{\mathrm{o}}=$ minimum sample size required for infinite population

$\mathrm{p}=$ pre-study estimate of the proportion of nurses in Fako Division (and has a standard value of $50 \%$ or 0.5 )

$$
\mathrm{q}=1-\mathrm{p}
$$

$\mathrm{d}=$ the degree of precision or the accuracy $(=5 \%$ or 0.05$)$

$\mathrm{z}=$ standard normal variant at confidence level of $95 \%$ (normal value is 1.96)

Hence,

$$
\text { Sample size } \begin{aligned}
\left(\mathrm{n}_{\mathrm{o}}\right) & =(1.96)^{2}(0.5)(0.5) /(0.05)^{2} \\
& =0.9604 / 0.0025 \\
& =384.6 \text { persons } \\
& =385 \text { person }
\end{aligned}
$$

The number of participants determined above (385 persons) is an infinite population

However, the population of nurses on a previous study conducted in Fako division, $\mathrm{N}$ is about 402.

Therefore the minimum sample size required for the finite 
population, $\mathrm{n}$, will be calculated as

$$
\begin{aligned}
& \mathrm{n}=\frac{\mathrm{n}_{\mathrm{o}}}{1+\frac{\mathrm{n}_{0}}{N}} \\
\mathrm{n} & =385 /(1+385 / 402) \\
& =385 / 1.958 \\
& =196.62
\end{aligned}
$$

Thus the study will include 197 participants.

We had a total return of 185 answered questionnaires giving a response rate of $94.1 \%$

\subsection{Study Procedure}

- Ethical approval and administrative procedures

Research clearance was obtained from the Institutional Review Board in the Faculty of Health Sciences in the University Buea. This clearance acted as a supporting document to facilitate the collection of data from the field.

Secondly, permission was also obtained from the regional delegation of health and all the eight health institutions through letters written to the hospital administration explaining the goals and the importance of the research and asking for permission to collect data.

Thirdly, the approved questionnaires were pre-tested in a selected hospital which was not part of the study.

- Participant Recruitment

Before the participants were selected for the study, a brief explanation was done on the goal of the research and basic clarifications were made on areas of doubt so that the participants were clarified about the purpose of the research.

Participants were informed that the research was strictly for academic purposes and so they were not to expect any payment for their participation. Participants were met on duty at their various break periods so as not to interfere with their work schedule.

\subsection{Data Collection}

Data was collected using a questionnaire. A brief explanation on the purpose of the study was made and clarifications done where needed. A signed consent form of those who were willing to participate was obtained after they had shown full understanding of the study then questionnaires were distributed for them to fill. Questionnaires were filled by the participants under the supervision of the principal investigator to ensure accuracy of data obtained. Each participant had a maximum of 30 minutes to provide answers in the questionnaires.

\subsection{Data Management and Analysis}

Data collected were kept safely at the end of the research to prevent loss of important information. Results keyed into the computer were secured using a password to secure participant information and prevent unwanted access. This information was later copied unto a Compact Disc (CD) to serve as a reserve and for storage.

For the quantitative data, a pre-designed EpiData Version 3.1 (EpiData Association, Odense Denmark, 2008) database which has in-built consistency and validation checks was used to enter the data. For further consistency, data range and validation checks were also performed in SPSS (Statistical Package for Social Sciences) version 21.0 (IBM Inc., 2012) to identify invalid codes. Data were made essentially of categorical variables and they were analyzed using frequency and proportions and Multiple Response Analysis to aggregate responses within conceptual components. Reliability test was performed to assess the internal consistency of responses using Cronbach Alpha reliability analysis. Chi-Square test of equality of proportion was used to compare proportions for significant difference. Data were presented using frequency table, charts and code-grounding-quotation table. All statistics were presented at the $95 \%$ Confidence Level (CL), Alpha $=0.05$.

\section{Results}

This study involved three categories of hospitals which are Mission hospitals, Private Hospitals and Public Hospitals.

Of the total of 197 questionnaires we have a total return of 185 giving a return rate of $94.1 \%$

All the three types of institutions were represented in the sample where by $84(45.4 \%)$ were public, $72(38.9 \%)$ were mission and 29(15.7\%) were private hospitals.

Table 2. Frequency distribution of questionnaires by Health institutions

\begin{tabular}{llll}
\hline Institutions & Frequency & Percent & $\begin{array}{l}\text { Valid } \\
\text { Percent }\end{array}$ \\
\hline Regional Hospital Buea & 37 & 20.0 & 20.0 \\
Regional Hospital Limbe & 18 & 9.7 & 9.7 \\
District Hospital Muyuka & 29 & 15.7 & 15.7 \\
Regina Pacis Health Center Mutengene & 6 & 3.2 & 3.2 \\
Mount Mary Hospital Buea & 18 & 9.7 & 9.7 \\
Baptist Hospital Mutengene & 48 & 25.9 & 25.9 \\
St. Lukes Medical Center Buea & 17 & 9.2 & 9.2 \\
Solidarity Clinic Buea & 12 & 6.5 & 6.5 \\
Total & 185 & 100.0 & 100.0 \\
\hline
\end{tabular}

As part of the objective which was to know the reason why Nurses choose the profession, the following result was found.

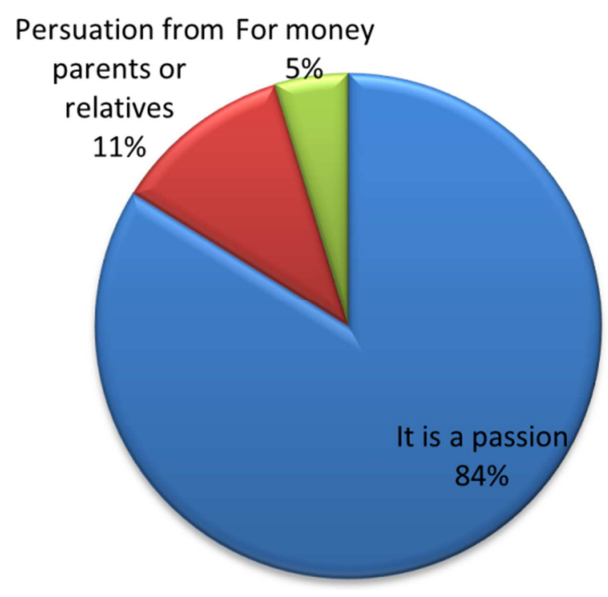

Figure 1. Nurses and their choice of qal v profession. 
Nurses mostly chose the profession out of passion $(84 \%)$ and few did so for financial benefits $(5 \%)$

a). Intrinsic motivation

Intrinsic motivation was generally perceived by nurses as a major determinant of service rendered $82.8 \%$ (MRS: $\left.\mathrm{n}_{\text {responses }}=613\right)$. The most highlighted motivation type was Recognition with $169(91.4 \%)$ and the least was 'More responsibilities with $119(64.3 \%)$.

Table 3. Perceived intrinsic motivation to nurses output.

\begin{tabular}{|c|c|c|c|c|}
\hline Intrinsic motivation & Agree & Disagree & Not sure & $\mathbf{N}$ \\
\hline Success or achievement that you get from the hospital motivates you & $158(85.4 \%)$ & $11(5.9 \%)$ & $16(8.6 \%)$ & 185 \\
\hline Recognition as important in the hospital motivates you & $169(91.4 \%)$ & $6(3.2 \%)$ & $10(5.4 \%)$ & 185 \\
\hline Promotion motivates you to work better & $167(90.3 \%)$ & $10(5.4 \%)$ & $8(4.3 \%)$ & 185 \\
\hline More responsibilities motivates you & $119(64.3 \%)$ & $35(18.9 \%)$ & $31(16.8 \%)$ & 185 \\
\hline MRS(Aggregated score based on responses) & $613(82.8 \%)$ & $62(8.4 \%)$ & $65(8.8 \%)$ & 740 \\
\hline
\end{tabular}

Were $\mathrm{N}=$ The total number of Participants in the study.

Perceived Intrinsic motivation to nurses output by background information

Nurses perception of the importance of motivation in service output did not differ significantly by institution type, age, gender, qualification and work experience $(\mathrm{P}>0.05)$.

Table 4. Distribution of perceived intrinsic motivation by background information.

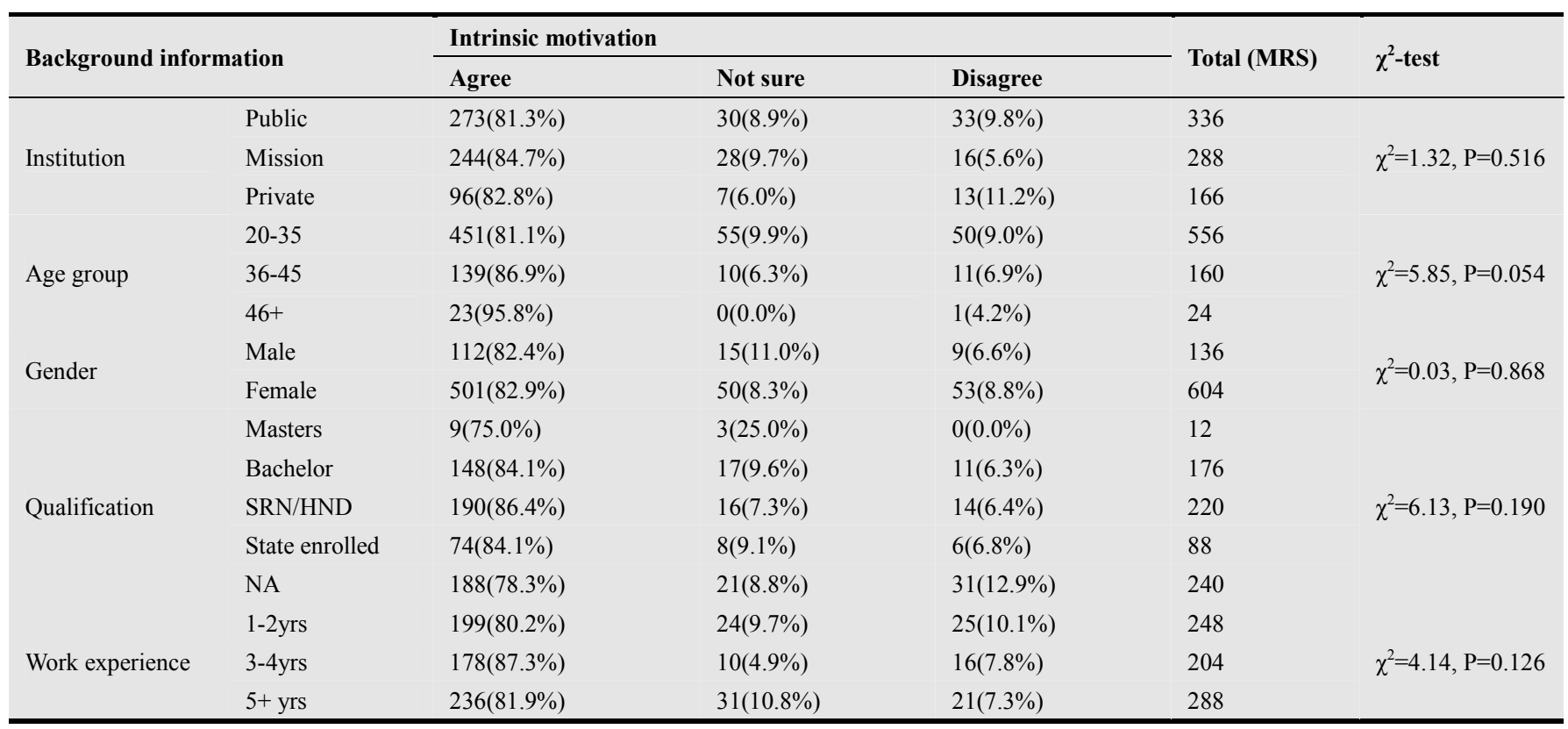

Where MRS is the Aggregate score base on response on all the 4 questions asked on intrinsic motivation comparing with the background information so as to easily get the statistical difference.

b). Extrinsic motivation

Perceived extrinsic motivation to nurses output
Extrinsic motivation was perceived by nurses as relatively important determinant of service rendered as only a weak majority of them so agreed $\mathrm{MRS}=59.4 \%$ ((MRS: $\mathrm{n}_{\text {responses }}=549$ ). The most highlighted motivation type was Increase in salary or bonus $157(84.9 \%)$ and the least was Flexible or loose hospital policies 67(36.2).

Table 5. Perceived extrinsic motivation to nurses output.

\begin{tabular}{|c|c|c|c|c|}
\hline Extrinsic motivation & Agree & Disagree & Not sure & $\mathbf{N}$ \\
\hline Does increase in salary or bonus encourage you to work better & $157(84.9 \%)$ & $12(6.5 \%)$ & $16(8.6 \%)$ & 185 \\
\hline Does strict or constant hospital supervision affect the way you care for & $96(51.9 \%)$ & $61(33 \%)$ & $28(15.1 \%)$ & 185 \\
\hline Do strict hospital policies encourage you to work better & $109(58.9 \%)$ & $39(21.1 \%)$ & $37(20 \%)$ & 185 \\
\hline Do flexible or loose hospital policies encourage you to work better & $67(36.2 \%)$ & $80(43.2 \%)$ & $38(20.5 \%)$ & 185 \\
\hline $\begin{array}{l}\text { Do working conditions including long working hours and shift exchange affect the care you render } \\
\text { to patients }\end{array}$ & $120(64.9 \%)$ & $46(24.9 \%)$ & $19(10.3 \%)$ & 185 \\
\hline MRS (Aggregated score based on responses) & $549(59.4 \%)$ & $238(25.7 \%)$ & $138(14.9 \%)$ & 925 \\
\hline
\end{tabular}


Perceived extrinsic motivation to nurses output by background information

Nurses perception of the importance of motivation in service output did not differed significantly by age, gender, qualification and work experience $(\mathrm{P}>0.05)$ but it was realized that 95 nurses working in private hospitals the most perceived the importance of extrinsic motivation $\left(\chi^{2}=6.03 ; \mathrm{P}=0.049\right)$.

Table 6. Distribution of perceived extrinsic motivation to nurses output by background information

\begin{tabular}{|c|c|c|c|c|c|c|}
\hline \multirow{2}{*}{\multicolumn{2}{|c|}{ Background information }} & \multicolumn{3}{|c|}{ extrinsic motivation } & \multirow{2}{*}{$\mathbf{N}$} & \multirow{2}{*}{$\chi^{2}$-test } \\
\hline & & \multirow{2}{*}{$\begin{array}{l}\text { Agree } \\
232(55.2 \%)\end{array}$} & \multirow{2}{*}{$\begin{array}{l}\text { Not Sure } \\
55(13.1 \%)\end{array}$} & \multirow{2}{*}{$\begin{array}{l}\text { Disagree } \\
133(31.7 \%)\end{array}$} & & \\
\hline \multirow{3}{*}{ Institution } & Public & & & & 420 & \multirow{3}{*}{$\chi^{2}=6.03, P=0.049$} \\
\hline & Mission & $222(61.7 \%)$ & $70(19.4 \%)$ & $68(18.9 \%)$ & 360 & \\
\hline & Private & $95(65.5 \%)$ & $13(9.0 \%)$ & $37(25.5 \%)$ & 145 & \\
\hline \multirow{3}{*}{ Age group } & $20-35$ & $406(58.4 \%)$ & $110(15.8 \%)$ & $179(25.8 \%)$ & 695 & \multirow{3}{*}{$\chi^{2}=1.08, \mathrm{P}=0.583$} \\
\hline & $36-45$ & $125(62.5 \%)$ & $26(13.0 \%)$ & $49(24.5 \%)$ & 200 & \\
\hline & $46+$ & $18(60.0 \%)$ & $2(6.7 \%)$ & $10(33.3 \%)$ & 30 & \\
\hline \multirow{2}{*}{ Gender } & Male & $109(64.1 \%)$ & $27(15.9 \%)$ & $34(20.0 \%)$ & 170 & \multirow{2}{*}{$\chi^{2}=1.96, \mathrm{P}=0.161$} \\
\hline & Female & $440(58.3 \%)$ & $111(14.7 \%)$ & $204(27.0 \%)$ & 755 & \\
\hline \multirow{5}{*}{ Qualification } & Masters & $9(60.0 \%)$ & $5(33.3 \%)$ & $1(6.7 \%)$ & 15 & \multirow{5}{*}{$\chi^{2}=0.68, P=0.954$} \\
\hline & Bachelor & $129(58.6 \%)$ & $37(16.8 \%)$ & $54(24.5 \%)$ & 220 & \\
\hline & SRN/HND & $169(61.5 \%)$ & $38(13.8 \%)$ & $68(24.7 \%)$ & 275 & \\
\hline & State enrolled & $65(59.1 \%)$ & $16(14.5 \%)$ & $29(26.4 \%)$ & 110 & \\
\hline & NA & $175(58.3 \%)$ & $42(14.0 \%)$ & $83(27.7 \%)$ & 300 & \\
\hline \multirow{3}{*}{ Work experience } & $1-2 y r s$ & $181(58.4 \%)$ & $49(15.8 \%)$ & $80(25.8 \%)$ & 310 & \multirow{3}{*}{$\chi^{2}=3.29, \mathrm{P}=0.193$} \\
\hline & $3-4 y r s$ & $142(55.7 \%)$ & $44(17.3 \%)$ & $69(27.1 \%)$ & 255 & \\
\hline & $5+\mathrm{yrs}$ & $226(62.8 \%)$ & $45(12.5 \%)$ & $89(24.7 \%)$ & 360 & \\
\hline
\end{tabular}

Where MRS is the Aggregate Score base on the 5 questions asked on extrinsic motivation comparing with the background information so as to easily get the statistical difference.

\section{Discussion}

This study sought to identify motivational factors that influence nurses' output, The findings revealed that majority of nurses $(84 \%)$ choose the profession out of passion as supported by Boughn [2] who did a similar study and concluded that, reasons why people choose the carrier of nursing is the desire to help or care for others and to contribute to the society.

We found out that, with intrinsic motivation, $85.4 \%$ of nurses were motivated when they are successful and have achievements like new knowledge, skills and ability to grow when working in the hospital as supported by Muller- Smith [10] who concluded that, nurses who realized that there is potential for growth rather than fear of loss of invested energy and excitement will lead to a joyful workplace and a strong sense of accomplishment.

Recognition or full appreciation of work done is ranked the first of the motivated intrinsic factors with $(91.4 \%)$, thus indicating that most nurses wish to be recognized for a job well done. This is confirmed by a similar study done by Wiley [11] who also ranked this factor first in 1946 and consistently ranked second between 1980 and 1922. In another study, Campbell et al [14] found out that nurses needed more recognition to satisfy their needs for reputation, prestige to respect from others which eventually increase self esteem
In this study, Promotion (90.3\%) ranked second among the intrinsic factors. This result is confirmed by similar work carried out by Ebong [15]. but it opposes other studies like Kovach, [12], Wiley, [11] and Lindner [13] who ranked the same factor 6th -4 th and 5th places respectively. The ranking of promotion at the second position highly supports the Herzberg theory as being a motivator among nurses. Also Yin and yang [16] carried out a study and viewed that power and position would give high probability for workers to stay in institutions. This is because with their positions they feel motivated when they participate and take part in decision making and influence coordination.

From the findings, it is shown that when nurses have a lot of responsibilities $(64.3 \%)$ they feel motivated, This is in line with the study done by May [6] who explains that nurses feel motivated when they know responsibility and autonomy is bestowed on them. Khowaja et al [17] strengthens this finding in his study and said lack of autonomy among nurses, in adequate staffing and work overload could affect job satisfactions which also affects nursing care and output.

In addition, we also found out that, Intrinsic motivation was considered as the main factor of motivation among the nurses with $82.8 \%$ and an aggregate score base of 613 . This ties with the Herzberg two factor theory in which he considers intrinsic factors as motivators and is the type of motivation that employees' desire [4].

With the extrinsic motivation, majority of the nurses agreed that increase in salary and bonus was a motivating factor. This ranked first among the extrinsic factors having $(84.9 \%)$ as against $(6.5 \%)$ of those who disagree. This is in line with the study done by Yin and Yang, [16], who said 
nurses who are well paid in terms of salary and fringe benefits are satisfied and they work relentlessly. On the other hand, salary was considered a hygienic factor in any job, Herzberg, [4], recommended that increase in salary or wages motivated people but they are expected to seek the next wage increase. But Liou et al, [9] made the claim that salary increment is considered as the main aspect which increases job satisfaction among nurses.

Results from the research also showed that $(51.9 \%)$ of nurses are for the claim that strict (constant) hospital supervision will affect their services rendered to their patients. This finding contradicts the findings done by Nillsson and Stomberg [18] who revealed that opportunity for growth, working condition and supervision help increase performance in working.

The results also indicated that most nurses prefer strict hospital polices $(58.9 \%)$ because it encouraged them to work better as against $(36.2 \%)$ for those who preferred loose hospital polices This is supported by the study done by Saiyadin [19] who assumed that some employees considered company policies such as contest for best workers at the end of the year, certificate for outstanding employees and publication of good performance within the company as aspects which motivates them for a better output.

We also found out that, majority of nurses cited that unfavorable working conditions $(64.9 \%)$ affect the care they provide to their patients. This finding contradicts that done by Nilsson and Stomberg [48] which revealed that opportunities for growth, working conditions and supervision help to increase nurses' performance; It is also known that employees have problems when their working hours are extended than normal and social conditions [20]. This also goes in line with Herzberg [4] who said working conditions are considered as hygienic or dissatisfies and if not met or present will not motivate individuals to higher and better performance. In addition, the results revealed that there was a significant difference in extrinsic motivation among nurses working in private hospitals since they valued extrinsic motivation more compared to those in the public and mission hospitals. A study done in Jordan indicates that nurses in private hospitals are more satisfied and had higher intensions to stay then those in public hospitals [21].

Generally, it showed that nurses valued to intrinsic motivation $(82.8 \%)$ as compared to extrinsic motivation (59.4\%). These ties with Herzberg theory who said motivators (intrinsic factors) highly led to job satisfaction compared to extrinsic factors (dissatisfies) [4].

\section{Conclusion}

From this quantitative study, we can conclude that nurses choose the profession out of passion.

The two factors of motivation have an influence on nurses' output; intrinsic motivation is seen as the dominant and most requested motivated factor by nurses with more emphasis on recognition and promotion. Followed by extrinsic motivation with the most emphasis placed on salaries and bonuses, there was a statistical difference as nurses in the private hospitals desired extrinsic motivation more.

\section{Recommendation}

- We therefore recommend that nurses should enter the nursing field for passion and love for the profession but not for the monetary aspect because it will affect their output.

- Administrators in institutions should focus on motivating nurses intrinsically especially promoting and recognizing them and also on salary increment when need be.

\section{Limitation to Study}

- Some questionnaires giving to study participants were not returned giving a lesser number than the estimated sample size.

\section{Competing Interests}

The authors declare no conflict of interest in designing, conducting and reporting the findings of this work.

\section{References}

[1] Meyer T. J., Peng M. L.: Job Motivation and Attitude to Work. Lagos: Saban Publishers; 2006.

[2] Boughn S.: Why women and men choose nursing. Nurs Health Care Perspect 2001, 22: 14-19.

[3] Prater L., McEwen M: Called to nursing: Perceptions of student nurses. J Holist Nurs 2006, 24: 63-69.

[4] Herberg F.: One More Time: How Do You Motivate Employees. Harv Bus Rev 1987, 81: 86-96.

[5] White R W.: Motivation reconsidered. Psychol Rev 1959, 66: 297-333.

[6] May A. A.: A study of nurse practitioner job satisfaction in Florida. Unpublished master's thesis. Fla State Univ Coll Nurs 2008.

[7] Tang J H: Evidence-based protocol: nurse retention. $J$ Gerontol Nurs 2003, 29: 5-14.

[8] Deci E. L., Ryan R. M.: Intrinsic Motivation and SelfDetermination in Human Behavior. New York: Plenum; 1985.

[9] Liou C N., Shi W. H., Tseng K. Y.: Job satisfaction of a medical centers'nurses and related

[10] Muller-Smith P.: The energy business. J Perianesthetic Nurs 1999, 14: 300-302.

[11] Wiley C.: What motivates employees according to over 40 years of Motivation surveys. Int J Manpow 1997, 18: 264 280.

[12] Kovach K. A.: What motivates Employees? Workers and Supervisors give different answers. Bussiness Horiz 1987, 30: $58-65$. 
[13] Linder J. R.: Understanding employee Motivation. J Ext 1998, 3: $1-8$.

[14] Campbell S L., Fowles E R., Weber B J.: Organisational structure and job satisfaction in public health nursing. Public Health Nurs 2004, 2: 564-571.

[15] Ebong P. A.: Assesing the role of work motivation on employee performance. Umea Sch Bussiness Econ 2009.

[16] Yin, JT, Yang, KA: Nursing turnover in Taiwan: a metaanalysis of related factors. Int J Nurs Stud 2002, 39: 573-581.

[17] Khowaja, K., Merchant, RJ, Hirani, D: Registered nurses' perception of work satisfaction at a tertiary care university hospital. J Nurs Manag 2005, 13: 32-39.
[18] Nillsson K E., Stomberg M I. W.: Nursing students' motivation towards their studies: a survey study. BioMed Cent Nurs 2008, 7: 6.

[19] Saiyadain Mirza: Human Resources Management. McGrawhill; 2009.

[20] Karatepe M. O., Uludag O.: Conflict, exhaustion and motivation: a study of frontline employees in Northern Cyprus hotels. Hosp Manag 2007, 26: 645-665.

[21] Mrayyan M T.: Nurse job satisfaction and retention: comparing public to private hospitals in Jordan. J Nurs Manag 2005, 13: 40-50. 